Article

\title{
The Interpretation of Pronouns across Spanish-Speaking Populations
}

\section{Sergio Baauw}

Department of Languages, Literature and Communication, Utrecht Institute of Linguistics OTS, Universiteit Utrecht, Heidelberglaan 8, 3584 CS Utrecht, The Netherlands; s.baauw@uu.nl; Tel.: +31-(0)30-253-9689 or +31-(0)61-540-5374

Received: 24 December 2017; Accepted: 11 April 2018; Published: 20 April 2018

\begin{abstract}
In this paper, we will present data from both Spanish acquisition and aphasia on the Pronoun Interpretation Problem (PIP), according to which children allow pronouns to be identified with local c-commanding antecedents. Although it has recently been claimed that the PIP is, to a great extent, an experimental artifact, there are good reasons to believe that there is something "real" in the effect. As with many phenomena from acquisition, researchers have tried to explain this development in terms of "learning", or more concretely, in terms of "parameter setting". Children either must set the right local domain for the application of Principle B or they must set a + / - Principle B parameter. However, considering the PIP as an acquisition problem is problematic since it is difficult to see how children can converge on the target grammar without negative evidence. In this paper, we will defend an alternative approach, according to which the PIP is portrayed as the result of interplay between properties of predicates and different kinds of pronouns on the one hand, and language processing factors on the other.
\end{abstract}

Keywords: binding; co-reference; Principle B; A-Chains; agrammatism; processing; economy; clitic pronouns; Exceptional Case Marking constructions; picture selection; picture verification

\section{Introduction}

It is a well-known finding that English five-year-old children have problems with the interpretation of personal pronouns, as in (1a), allowing them to be identified with local subjects. Typically, at the same age they do not seem to have the same problems with reflexives (1b) (Chien and Wexler 1990, a.o.):

1. a. Mama bear touched her

$$
\text { [her }=\text { Mama bear, 50\% acceptance] }
$$

b. Mama bear touched herself [herself $=$ Goldilocks, $10 \%$ acceptance]

This phenomenon, which we will call the Pronoun Interpretation Problem (PIP), normally disappears when the child reaches the age of seven.

Although it has recently been claimed that the PIP is, to a great extent, an experimental artifact (Conroy et al. 2009), in this paper we will discuss several published studies that show that the PIP is a real effect and that it is the result of the interplay between properties of different kinds of predicates and pronouns on the one hand, and language processing factors on the other. We will argue that this approach fares better in explaining the available data than alternative approaches that considered the PIP to be the result of incorrect or incomplete parameter setting.

We will make our case using data from Spanish and other languages, and from both acquisition and aphasia. 


\section{The Pronoun Interpretation Problem as a Real Phenomenon}

Conroy et al. (2009) argued that the PIP found in child language development is an experimental artifact. They argue that previous experiments using a Truth Value Judgment Task (TVJT), such as Thornton and Wexler (1999), did not really respect the condition of plausible dissent (Crain and Thornton 1998). In the context of a TVJT, this condition states that a "no" response is only felicitous if the situation that would have led to a "yes" response has been considered by the child. This only happens if this situation has been a live option in the storyline of the trial. According to Conroy et al. (2009), this was not the case in many previous studies in which the stories of the trials revolved completely around one individual (e.g., Bert) who was the sentence internal antecedent in the test sentences with referential subjects (2a). Interestingly, in the sentences with a quantified subject (2b), this individual was the sentence external antecedent. According to Conroy et al. (2009), the prominence of the sole antecedent (Bert) led five-year-old children to accept co-reference in 50\% of the cases in (2a) but in only $15 \%$ of the cases in (2b). This difference in performance, found in some studies, was argued to be the result of children's observance of Principle B (violated if every reindeer binds the pronoun him), and their frequent acceptance of local co-reference between a pronoun and a local c-commanding referential Determiner Phrase (DP), due to children's difficulties with the pragmatic constraints on local co-reference (Chien and Wexler 1990).

2. a. Bert brushed him

b. Every reindeer brushed him

Conroy et al. (2009) designed an experiment in which they "repaired" the flaws of earlier studies, carefully respecting plausible dissent, giving all potential antecedents equal prominence. The results showed a radical drop of the percentage of non-adult-like "yes" responses in sentences such as (2a) to $11 \%$, and the disappearance of a significant contrast between (2a) and (2b), which led to $14 \%$ non-adult-like "yes" responses. The PIP reappeared in (2a) when the flaws of earlier studies were reintroduced in the design.

Although Conroy et al. (2009) convincingly showed that five-year-old children master Principle B and the principles regulating local (pragmatic) co-reference, this does not necessarily mean that the PIP is exclusively an artifact. As they admit, earlier studies showed cross-linguistic differences with respect to the presence of a PIP in acquisition. Spanish-speaking children, for instance, did not show a PIP in sentences such as (3), despite an experimental setup that did not respect plausible dissent (Baauw 2000):

3. La niña la señala

'The girl pointed at her.'

Similar results were found for languages such as French (Hamann et al. 1997), Catalan (Escobar and Gavarró 1999) and Italian (McKee 1992; Berger 1999), all languages in which the weak pronoun is a syntactic clitic, an element reported to resist local co-reference (Delfitto 2002).

Also, if the PIP were an experimental artifact-the result of the unbalanced prominence that is given to the sentence internal antecedent-it is not clear why it showed up in older picture verification studies (Chien and Wexler 1990; Koster 1993; Philip and Coopmans 1996; a.o.), in which the potential antecedents were not introduced by any story, and for that reason had similar prominence (or lack of it).

\section{The Pronoun Interpretation Problem as Incomplete Learning}

Like many phenomena from acquisition, researchers have tried to explain child language development in terms of "learning", or more concretely, in terms of "parameter setting". Binding and co-reference were no exception to it. 
One specific proposal along these lines is McKee (1992). Her proposal is based on Manzini and Wexler's (1987) parameter setting proposal. They argue that the local domain in which Principle B is applied, the Governing Category (GC) is parameterized. In some languages, such as English, Dutch or Spanish, it is the minimal XP (i.e., a maximal projection) that contains the pronoun, an accessible subject, and its governor (Chomsky 1981). In other languages the GC may be different. The learning task of children is to set this parameter at the language-specific value. McKee (1992) argues that English-speaking children initially assume the GC to be the Verb phrase (VP) (4b). This means that for them the pronoun must be free inside the VP but can be freely bound by the subject in the specifier of the Inflection Phrase ([Spec, IP]), leading to the acceptance of the reflexive interpretation of (1). McKee (1992) also accounts for the absence of a PIP in the acquisition of Italian (and by extension, in Spanish). Since in Italian the weak pronoun is a syntactic clitic, it is not inside the VP, but in a position adjoined to I (4a). This extends automatically the GC to the IP, making binding by the subject in [Spec, IP] impossible without violating Principle B, which is considered to be innate and inviolable.

\begin{tabular}{|c|c|}
\hline a. & $\begin{array}{c}\text { [IP Lo gnomo } \\
\text { the gnome }\end{array}$ \\
\hline
\end{tabular}
b. [IP The gnome
[VP washed
him]]

A different approach is taken by Elbourne (2003; cited by Elbourne 2005). He proposes that Principle B itself may be subject to parameterization. In some languages it is active, such as in Modern English, and in others it is inactive, such as in Middle English. Elbourne (2003) assumes that English-speaking children start out with a grammar in which Principle B is inactive, as in Middle English. A slightly different approach is taken by Fodor (1992; cited by Elbourne 2005). She argues that children may analyze pronouns such as him initially as ambiguous between a pronoun and a weak reflexive, such as Dutch zich in (5). When they analyze him as zich, the pronoun can be bound without violating Principle B.

$$
\begin{array}{lll}
\text { 5. a. Jan waste zich } \\
\\
\text { John washed REFL } \\
\text { 'John washed (himself).' }
\end{array}
$$

Chien and Wexler (1990) argued that children obey (innate) Principle B, rejecting local binding of the pronoun, but that they often accept local co-reference in contexts in which adults would reject such an interpretation. This explained why English-speaking five-year-olds accepted the reflexive interpretation much more often in (6a) than in (6b).

6. a. Mama Bear is touching her [50\% target-like performance]

b. Every bear is touching her [85\% target-like performance]

In (6a) the pronoun can be identified with the local subject through variable binding, which would lead to a violation of Principle B, but also through local (pragmatic) co-reference. In the adult language, local co-reference is limited to special contexts, such as in (7) (Heim and Kratzer 1998).

7. a. Everybody hates John. Mary hates him, Peter hates him, even John hates him.

b. Do you know what Mary and John have in common? Mary admires him and John admires him too.

Children, on the other hand, are argued to often accept local co-reference also outside these special contexts. According to Chien and Wexler (1990), this is because they still must learn the pragmatic constraints on local co-reference, constraints that Chien and Wexler (1990) call Principle P.

In (6b), on the other hand, the pronoun can only be identified with the local subject through variable binding, since quantified DPs cannot co-refer. However, since binding violates Principle B, and Principle B is assumed to be respected by children, a reflexive reading of (6b) cannot be construed. 
Crucially, the assumption is that pragmatic principles, such as Principle $\mathrm{P}$, must be acquired by children, unlike syntactic principles, such as Principle B, which are assumed to be universal and innate.

Most accounts that assume some sort of incomplete acquisition, either as incorrect parameter setting (McKee 1992; Elbourne 2003) or as incomplete pragmatic acquisition (Chien and Wexler 1990), face the problem of having to explain the optionality of children's acceptance of local co-reference. If a pragmatic principle is not in place or a parameter is incorrectly set, the child is expected to perform consistently in accordance with this stage of language-specific competence, accepting the reflexive interpretation of (1a) across the board, and not roughly $50 \%$ of the time, as is found in many studies.

Another problematic aspect of this approach is the fact that the PIP is only found in comprehension, not in production. Bloom et al. (1994) have shown that the PIP is absent in spontaneous production of English-speaking children. Experimental language production studies show no evidence of a PIP either. An elicited production study by De Villiers et al. (2005) showed that English-speaking children with a mean age of 6;2 produced pronouns, in conditions eliciting reflexives, only between $0 \%$ and $14 \%$ of the time (depending on the kind of sentence).

Finally, incomplete acquisition accounts face a learnability problem. A child that allows both local and non-local reference of the pronoun at some point must retreat to a system in which only non-local reference is possible. The question is how the child can do this in the absence of negative evidence. Some authors have argued that there may be triggers in the input that signal the target parameter setting (McKee 1992). However, the question remains why children are not sensitive to these triggers from the beginning.

\section{The Pronoun Interpretation Problem as a Processing Problem}

In this section, we will defend an alternative approach to the PIP, according to which it is the result of the interplay between properties of predicates and different kinds of pronouns, on the one hand, and language processing factors, on the other (Avrutin 1994, 2004; Avrutin and Baauw 2013; Baauw et al. 2011).

\subsection{The Pronoun Interpretation Problem Cross-Linguistically}

We will adopt Grodzinsky and Reinhart's (1993) account of the PIP in sentences such as (6). They propose that children obey Principle B, which explains why they perform highly target-like on (6b). The reason they often accept the reflexive interpretation of (6a) is because children often accept local co-reference in contexts in which adults with no language pathologies reject this reading. This is due to children's difficulties with the application of a discourse-syntax interface constraint on local co-reference, called Rule I. Rule I is invoked when a local co-reference interpretation is an option, such as in (6a). Children have difficulties with the application of this rule because it requires the comparison of two possible construals of the same sentence-the binding construal and the co-reference construal - to rule out the co-reference construal if it turns out to be indistinguishable from the binding construal. Grodzinsky and Reinhart (1993) argue that this reference set computation requires too many resources from the child's immature brain, causing Rule I to "break down". As a result, children start to guess to establish the reference of the pronoun, which leads them to accept co-reference in (6a) roughly $50 \%$ of the time.

However, there is considerable cross-linguistic variation with respect to the presence of a PIP in acquisition. The phenomenon has been found for English (Jakubowicz 1984; Chien and Wexler 1990), Dutch (Koster 1993; Philip and Coopmans 1996), Icelandic (Sigurjónsdóttir 1992) and Russian (Avrutin and Wexler 1992; Avrutin 1994), but not in many other languages, such as French (Hamann et al. 1997), Italian (McKee 1992), Catalan (Escobar and Gavarró 1999), Spanish (Baauw et al. 1997; Baauw 2000), Greek (Varlokosta 2000), Norwegian (Hestvik and Philip 2000) and Hungarian (Margócsy 2000). For Spanish, several picture verification task studies showed that five-year-old children accept the reflexive interpretation of (8) about $10 \%$ of the time (Baauw 2000; Baauw and Cuetos 2003; Alija and Baauw 2005). 
8. La niña la señala [la = la niña, $10 \%$ acceptance $]$

the girl her points-at

'The girl pointed at her.'

In Baauw (2000) it was argued that the factor that distinguishes languages with a PIP in their acquisition and those that do not show a PIP is the status of their weak pronouns. Concretely, no PIP is expected in the acquisition of languages in which the weak pronoun is a syntactic clitic (Baauw 2000). Baauw (2000) adopts Chien and Wexler's (1990) and Grodzinsky and Reinhart's (1993) proposal that the PIP is the result of children's non-adult-like acceptance of local co-reference. In languages with syntactic clitics, such as Spanish, the PIP does not show up because syntactic clitics resist local (pragmatic) co-reference, which prevents Rule I from being invoked. Baauw (2000) adopts Sportiche's (1992) view that clitics are VP external functional projections that host in their specifier a moved null object. The trace that is left by this movement is argued to convert the structure c-commanded by the specifier of the clitic phrase into a predicate (Heim and Kratzer 1998; Neeleman and Weerman 1999; Delfitto 2002). Subsequent application of Quantifier Raising of the subject DP and identification of the subject trace with the object trace under agreement (i.e., feature sharing) will lead to a clear violation of Principle B (9). ${ }^{1}$

$\begin{array}{lll}\text { 9. La niña } & \text { la } & \text { señala } \\ \text { the girl } & \text { her } & \text { points-at } \\ {[\lambda x(x \text { señala } x)](\text { la niña })} & \rightarrow \text { violation of Principle B }\end{array}$

Assuming that children respect Principle B, Spanish-speaking children will reject an interpretation in which the object is identified with the subject in (9). In sum, Spanish-speaking children's target-like performance on the interpretation of sentences such as (9) is similar to English-speaking children's target-like interpretation on (6b); the unavailability of a co-reference construal prevents children from showing a PIP.

The absence of a PIP in Spanish-speaking children's interpretation of sentences such as (8) shows that they respect Principle B, but also that they are aware of the syntactic clitic properties of Spanish weak pronouns. This is no surprise, since there is ample evidence that clitics are acquired early in acquisition. Research shows that Spanish- and Italian-speaking children learn very early that weak pronouns are syntactic clitics, and they hardly make errors with respect to the position of these elements (Guasti 1994; Ezeizabarrena 1996; Schaeffer 1997; Lyczkowsky 1999). Since the referential properties of syntactic clitics depend on their syntactic position (Baauw 2000; Di Sciullo and Agüero-Bautista 2008), rejection of local co-reference is expected as soon as they acquire the syntactic properties of clitics.

\subsection{What about Strong Pronouns in Romance?}

If the absence of a PIP in Romance (and some other) languages is due to the clitic status of their weak pronouns, then it is predicted to show up in structures with strong pronouns. Baauw (2000) carried out two experiments to discover a PIP in Spanish sentences containing strong pronouns.

In the first picture verification experiment, 32 Spanish-speaking children between 4;4 and 7;2 years of age (mean age $5 ; 11$ ) were tested on the reflexive interpretation of sentences such as (10a), with a

1 Note that the fact that clitic pronouns resist local (pragmatic) co-reference does not mean that they cannot be used for reference to non-c-commanding or sentence external DPs. In fact, sentences such as (i) clearly show that they can:

i. Juan saludó a María. Pedro también la saludó. [la = María] Juan greeted María. Pedro also her greeted

Baauw (2000) argues that in contexts in which disjoint reference of the object and the subject is intended, an empty topic is generated, which binds the object trace created by movement of the null object. This null topic can be identified in discourse with other DPs. For further elaboration of this proposal, see Delfitto (2002). 
clitic direct object pronoun, (10b), with a strong direct object pronoun, and (10c), in which the strong pronoun is the complement of a preposition. ${ }^{2}$

$\begin{array}{cclll}\text { 10. } & \text { a. } & \begin{array}{l}\text { El niño } \\ \text { the boy }\end{array} & \begin{array}{l}\text { le } \\ \text { himelitic }\end{array} & \begin{array}{l}\text { dibujó } \\ \text { drew }\end{array} \\ \text { b. } & \begin{array}{l}\text { El niño } \\ \text { the boy }\end{array} & \text { le } & \begin{array}{l}\text { dibujó } \\ \text { drew }\end{array} & \begin{array}{l}\text { a él } \\ \text { ACC-him }\end{array} \\ \text { c. } & \begin{array}{l}\text { El niño } \\ \text { the boy }\end{array} & \begin{array}{l}\text { miró } \\ \text { looked }\end{array} & \begin{array}{l}\text { hacia } \\ \text { at }\end{array} & \begin{array}{l}\text { él } \\ \text { him }\end{array}\end{array}$

The results showed no evidence of a PIP in sentences containing strong direct object pronouns. The reflexive interpretation was rejected $91 \%$ of the time in (10a) and $83 \%$ of the time in (10b). This difference was not significant. Baauw (2000) argues that the absence of a PIP in (10b) may be due to the obligatory presence of clitic doubling in Spanish structures involving strong direct object pronouns. Baauw (2000) proposes, following Aoun's (1999) analysis of doubled elements in Lebanese Arabic, that strong pronouns may be right-dislocated elements, which means that the object position in these constructions is occupied by the trace of a moved null-object, just as in the case of other pronominal clitic constructions (see also Fernández-Soriano (1989) for Spanish).

Although for Spanish a PIP could not be found in constructions containing strong direct object pronouns, in Italian Berger (1999) did find such an effect. She tested Italian-speaking children on the interpretation of sentences with direct object clitics, such as (11a), and sentences containing strong direct object pronouns, such as (11b).

$\begin{array}{clll}\text { 11. a. } & \begin{array}{l}\text { Il ragazzo } \\ \text { the boy }\end{array} & \begin{array}{l}\text { lo } \\ \text { him }_{\text {clitic }}\end{array} & \begin{array}{l}\text { sta indicando } \\ \text { is pointing-at }\end{array} \\ \text { b. } & \begin{array}{l}\text { Il ragazzo } \\ \text { the boy }\end{array} & \begin{array}{l}\text { sta indicando } \\ \text { is pointing-at }\end{array} & \begin{array}{l}\text { lui } \\ \text { him }_{\text {strong }}\end{array}\end{array}$

The results showed that children rejected a reflexive interpretation of (11a) but accepted it $61 \%$ of the time in (11b). This suggests that in constructions without clitic doubling, a PIP shows up with strong pronouns. ${ }^{3}$

However, Baauw (2000) also tested Spanish constructions in which strong pronouns are not doubled by clitics, namely constructions in which the strong pronoun is the complement of a preposition, as in (10c). The results show that, in this construction, the reflexive interpretation was rejected only $43 \%$ of the time by Spanish-speaking children. However, adult control participants showed a highly similar $51 \%$ rejection of (10c). This shows that the child performance cannot been interpreted as a PIP. In fact, in Spanish, strong pronouns can be identified with the subject of the verb in a wide range of prepositional constructions (13), whereas in languages such as English this possibility is limited to locative prepositions (12).

2 Since the testing took place in Madrid, and Madrid is a leista area, le was used instead of lo as the masculine direct object form (both are translated as him in English).

3 Some caution should be taken in interpreting these results. Berger (1999) also found that Italian children rejected the extra-sentential interpretation of the strong pronoun in (11b) $19 \%$ of the time. This may be due to the fact that strong pronouns are "marked" and usually used in contrastive contexts in which the pronoun tends to be stressed. As McDaniel and Maxfield (1992) notice, pronominal stress facilitates local, or "pragmatic", coreference. Researchers may try to pronounce the strong pronoun without stress, but this may sound unnatural, and could affect the results in unpredictable ways. 
12. a. Maryi put a chair behind her $_{i}$

b. $\quad{ }^{*}$ Mary $i$ only thought about her

13. a. María puso una silla detrás de ella $a_{i}$

Mary put a chair behind of her

b. María solo pensaba en ella

Mary only thought abouther

Apparently, locative Prepositional Phrases (PPs) can be analyzed as separate binding domains in both Spanish and English, but in Spanish some non-locative PPs should be considered separate binding domains too, allowing pronouns to be bound by the subject of the sentence. However, the possibility of non-locative PPs to be separate binding domains is subject to particular linguistic constraints; with some prepositions, a reflexive interpretation of the verb is more marginal than with others. Sentences containing these prepositions might allow us to see whether Spanish-speaking children show a PIP in sentences containing strong pronouns. However, this is only the case if we can somehow exclude the possibility that (more frequent) acceptance of a reflexive interpretation is due to children's possibly more "relaxed" constraints on the ability of PPs to be separate binding domains.

In order to control for this possibility, Baauw (2000) carried out a second picture verification experiment in which 30 Spanish-speaking children were tested (age range $4 ; 8-7 ; 3$, mean age 6;0) on the interpretation of sentences containing strong pronouns as the complement of non-locative prepositions that, according to native speakers, do not easily allow for a reflexive interpretation. These were presented either with a referential subject DP (14a), or with a quantified subject DP (14b). ${ }^{4}$

\begin{tabular}{|c|c|c|c|}
\hline 14. a. & $\begin{array}{l}\text { la niña } \\
\text { the girl }\end{array}$ & $\begin{array}{l}\text { sueña } \\
\text { dreams }\end{array}$ & $\begin{array}{l}\text { con ella } \\
\text { about her }\end{array}$ \\
\hline b. & $\begin{array}{l}\text { cada niña } \\
\text { every girl }\end{array}$ & $\begin{array}{l}\text { sueña } \\
\text { dreams }\end{array}$ & $\begin{array}{l}\text { con ella } \\
\text { about her }\end{array}$ \\
\hline
\end{tabular}

The reason sentences with quantified subjects were included is that quantified DPs cannot be identified with pronouns through co-reference; they can only bind them. This allows us to determine whether the acceptance of a reflexive reading is due to an over-acceptance of "pragmatic" co-reference by children, just like what happens in Dutch- and English-speaking children interpreting sentences such as (1a), or whether this acceptance is due to their across-the-board acceptance of PPs as separate binding domains. In that case, a reflexive interpretation could be a case of (non-local) binding instead of co-reference. The results showed that Spanish-speaking children rejected the reflexive interpretation of (14a) $42 \%$ of the time, and of (14b) $53 \%$ of the time. Adults rejected the reflexive interpretation of (14a) $72 \%$ of the time and of (14b) $89 \%$ of the time. An ANOVA showed that there was a main effect of sentence type (quantified DP/referential DP) and of group (children/adults). However, there was no interaction effect. This means that children rejected a reflexive interpretation less often than adults did, but that the extent to which they rejected this reading in sentences with quantified subject more often was not greater than in adults. ${ }^{5}$ This indicates that Spanish-speaking children's acceptance of the reflexive interpretation of (14a) (and of 14b) is due to children's less strict constraints on the

4 The experiment also tested strong pronouns in locative PPs. These data will not be discussed in this article. See Baauw (2000) for details.

5 Some native speakers resist binding of a strong pronoun by a quantified DP, also when the PP is allowed to be a separate binding domain, as in (ii) and (iii) (see Menuzzi 1996):

ii. $\%$ nadie $e_{i}$ vio cerca de él $l_{i}$ nobody saw a snake next to him 
establishment of PPs as separate binding domains, and not to problems with the application of the pragmatic constraints on local (pragmatic) co-reference (Rule I), as was argued to be the case in Dutchand English-speaking children. Probably, the availability of a binding construal that does not violate Principle B prevents Spanish-speaking children from establishing a co-reference relation between the strong pronoun and the subject.

\subsection{Structural Variation}

Philip and Coopmans (1996) noted that the intensity of the PIP depended on structural factors. They noticed that Dutch-speaking children show a much stronger PIP in Exceptional Case Marking (ECM) sentences, such as (15a) than in simple transitive sentences, such as (15b). Even 7-year-old rejected the reflexive interpretation of (15a) only $16 \%$ of the time, while they rejected (15b) $55 \%$ of the time.

15. a. het jongetje ziet hem dansen [hem $=$ het jongetje, $\pm 80 \%$ acceptance] the boy sees him dance

b. het jongetje aait hem [hem $=$ het jongetje, $\pm 50 \%$ acceptance] the boy pets him

A comparable difference in performance between ECM sentences and simple transitive sentences was also found in Spanish 5-year-olds (16) (Baauw et al. 1997; Baauw 2000; Baauw and Cuetos 2003), and in the acquisition of several other languages, such as French (Hamann et al. 1997), Italian (McKee 1992), Catalan (Escobar and Gavarró 1999), Greek (Varlokosta 2000), Norwegian (Hestvik and Philip 2000; Philip, pc) and Hungarian (Margócsy 2000). Below we provide the results of Baauw and Cuetos (2003), which used a picture verification task (disguised as a guessing game), with 38 five-year-old European Spanish-speaking children. The results are from the trials eliciting "no" responses in adults.

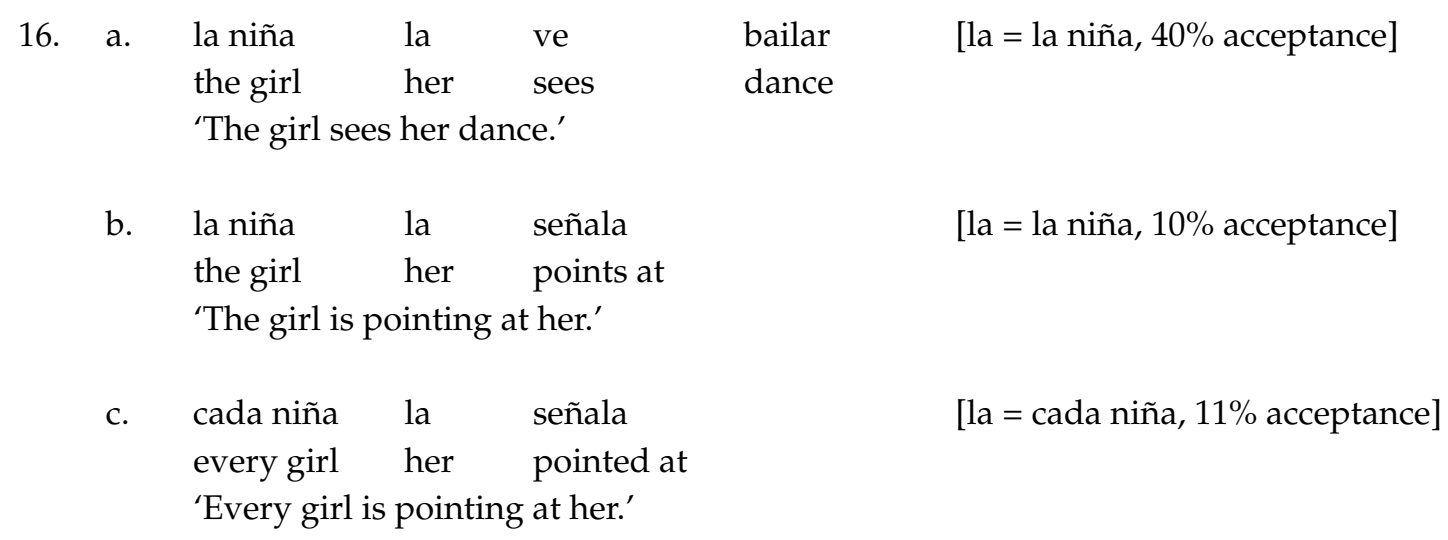

This difference in performance is not easy to explain in a framework that adopts standard Binding Principle B (Chomsky 1981), since this principle treats both sentence types alike; binding of the embedded pronominal ECM subject by the main clause subject would lead to a Principle B violation. In addition, the application and breakdown of Rule I in case the child tries to establish a co-reference relation should lead to a 50\% adult-like performance rate in both kinds of sentences in children acquiring languages such as Dutch, which has no Romance-like clitic pronouns, and around 90\% adult-like performance in children acquiring languages with syntactic clitics, such as Spanish.
iii. \%todo el mundo $\mathrm{o}_{\mathrm{i}}$ una culebra everybody
hablaba de él talked about him

This explains why even adults rejected the reflexive interpretation more often in (14b) than in (14a). 
However, the results fit easily in a framework that assumes an alternative formulation of the binding constraints. Reinhart and Reuland (1993) propose that the constraints on local binding are captured by two independent principles: a constraint on the creation of reflexive predicates, which they call Principle B, and a constraint on A-Chains, which they call the A-Chain Condition:

17. Principle B: A reflexively interpreted predicate must be reflexive-marked.

18. A-Chain Condition: A maximal A-Chain $\left(a_{1} \ldots a_{n}\right)$ contains exactly one link $-a_{1}-$ that is both $[+\mathrm{R}]$ and case-marked.

Reformulated Principle B, as in (17), can be seen as an interface filter on valency reduction (Reuland 2001). It limits the possibility of verbs to allow a reflexive interpretation ( $\lambda x \lambda y(x R y) \rightarrow \lambda x$ $(x R x))$ to those verbs in which reflexivity is somehow marked, either by means of a reflexive-marking morpheme or as a result of particular semantic properties. This principle can account for the ungrammaticality of the interpretation in which the object pronoun is bound by the subject of the same verb, as in (15b) or (16b). However, it cannot account for the ungrammaticality of the reflexive interpretation of (15a) and (16a). The reason is that in ECM constructions the subject of the main clause (het jongetje/la niña ('the boy'/'the girl')) and the pronominal subject of the embedded clause (hem/la ('him'/'her')) are not part of the same predicate; while het jongetje/la niña receives its thematic role from the main clause verb ziet/ve ('sees'), the pronoun hem/la receives its role from the embedded verb dansen/bailar ('to dance'). This means that when the main clause subject binds the subject of the embedded sentence, no reflexive predicate is created, rendering Principle B irrelevant. However, adult speakers reject such an interpretation. According to Reinhart and Reuland (1993), this is the result of the A-Chain Condition, as in (18). They argue that local binding relations lead to the creation of an A-Chain between the binder and the bindee. The A-Chain Condition states that the tail of this chain must be $[-R]$, i.e., a non-referential element. Simple reflexive pronouns such as Dutch zich are $[-R]$, but DPs and third person pronouns, such as hem 'him' or la 'her' are [+R]. As a result, binding of hem 'him' by het jongetje 'the boy' will lead to a violation of the A-Chain Condition, since both the head and the tail of the A-Chain are [+R]:

$\begin{array}{lll}\text { 19. het jongetje ziet } & {[\text { hem dansen] }} \\ \begin{array}{l}{[+\mathrm{R}]} \\ \text { 'the boy sees [him dance]' }\end{array} & \end{array}$

Therefore, it turns out that Dutch-speaking children show a stronger PIP in constructions where only the A-Chain Condition prevents an acceptable reflexive interpretation, and this turns out to be the only context in which Spanish-speaking children show a PIP. Philip and Coopmans (1996) and Baauw (2000) propose that this is due to children's ability to, optionally, interpret third-person pronouns as $[-R]$. When children interpret third-person pronouns as $[-R]$, the establishment of an A-Chain between the main clause subject and the embedded clause subject will not lead to a violation of the A-Chain Condition. Philip and Coopmans (1996) proposed that children's ability to treat third-person pronouns as $[-R]$ is due to incomplete feature acquisition. They follow Reinhart and Reuland's (1993) proposal that $[+R]$ is related to full specification for features such as number and structural case. Ambiguities in the Dutch pronominal system would cause a delay in case feature specification. Baauw (2000) proposed that incomplete acquisition of the feature [number] might be the cause of both Dutch- and Spanish-speaking children's ability to treat third-person pronouns as [-R]. However, as we argued before, incomplete acquisition proposals face the problem of having to explain the optionality that the child displays with respect to the interpretation of pronouns.

Baauw et al. (2011) and Avrutin (2006) therefore propose an alternative account, which is based on computational economy. Following Reuland (2001) and Avrutin (2004), they propose that the ungrammaticality of the reflexive reading of (15a) and (16a) is due to the violation of an economy condition on referential dependencies. Reuland (2001) argues that referential dependencies can be established in discourse (co-reference), in semantics (pronominal bound-variable construal) or in 
syntax (A-Chain). A-Chain formation is only possible between simple reflexives, such as Dutch zich, and a local c-commanding DP. This is because pronominal elements underspecified for [number], such as Spanish se and Dutch zich, forcibly establish a checking relation with local DPs. He further argues that syntactic dependencies are cheaper than dependencies built in semantics or discourse. This means that (20a) is ungrammatical because it is blocked by the more economical (20b).
20. a. *Jani ziet [hemi dansen]
'John sees him dance.'
b. Jan ziet [ [zich dansen]
A-Chain
'John sees REFL dance.'

(bound variable)

Baauw et al. (2011) and Avrutin (2006) propose that in populations with a reduced syntactic processing capacity, such as young children, bound variable construals and A-Chains may be equally economical, which will lead children to often accept (20a) as an alternative of (20b).

Note, finally, that the approach proposed here, in which the PIP is explained as the result of the interplay between structural and processing factors, accounts for the differences in performance between Dutch- and Spanish-speaking children in different syntactic contexts. In simple transitive sentences, Dutch-speaking children show a PIP, as a result of their limited processing ability, which affects the application of Rule I, an interface constraint on local co-reference. Spanish-speaking children do not show a PIP in these contexts, because weak pronouns are syntactic clitics in Spanish, and syntactic clitics do not allow local co-reference. This prevents Rule I from being invoked in Spanish, so that it cannot break down either. In ECM sentences Dutch-speaking children show an extra-strong PIP, since two independent causes of the PIP coincide; on the one hand, children may accept a bound-variable construal (20a) as an equally economical alternative for A-Chain formation (20b), due to their more limited syntactic processing capacity. On the other hand, children may accept local co-reference as an alternative for a bound-variable construal, due to a breakdown of Rule I. Spanish-speaking children, on the other hand, are only affected by the former cause; their more limited processing capacity will lead them to accept (21a) as an equally acceptable alternative of (21b), but they will not be affected by a breakdown of Rule I, because this constraint is never invoked in structures containing syntactic clitics, such as in Spanish. ${ }^{6}$
21. a. *la niñai lai ve bailar
'The girl sees her dance.'
(bound variable)
b. la niña $\underline{\text { se }}$ ve bailar
A-Chain
'The girl sees REFL dance.'
6 Note that the PIP in Spanish ECM sentences cannot be argued to be the result of the fact that the ECM sentence is longer. In Baauw (2000) it is shown that Spanish-speaking children reject the reflexive interpretation of (iv) $85 \%$ of the time.

$$
\text { iv. el niño trata de [PRO lavarle] }
$$
Similar results were found for Catalan (Escobar and Gavarró 1999).




\subsection{The Pronoun Interpretation Problem in Agrammatic Patients}

A strong argument in favor of a processing account of the PIP are populations that already have acquired language but lost their ability to use it in a target-like way. Patients with agrammatic Broca aphasia are such a population. They were in full command of a language but lost the ability to speak fluently because of brain damage. Typically, agrammatic patients have problems with the use of functional elements such as articles and tense, and with the interpretation of syntactic operations such as passive formation and wh-questions (Avrutin 2006). Grodzinsky et al. (1993) found a PIP in English-speaking agrammatic patients in sentences such as (1a), identical to children acquiring language. Vasic (2006) found a similar result in Dutch patients (see Ruigendijk et al. 2006 for an overview of several studies). Several researchers have claimed that agrammatic patients do not lose linguistic knowledge, but have problems with the applications of this knowledge, which leads them to show variability in their performance on syntactic operations (Avrutin et al. 1999; Kolk 1987).

Concretely, Avrutin $(1994,2004,2006)$ proposes that the similarities between child language acquisition and adult agrammatism are the result of a common problem with the processing of syntactic configurations. He argues that this processing limitation affects specifically those syntactic operations that are used to structure extra-syntactic (discourse, pragmatic) information. Although information of that kind can in principle also be conveyed by making use of other, extra-syntactic operations, the use of syntax is considered to be more economical in adult speakers with no language pathologies. This explains why adult speakers with no language pathologies normally use articles to express specificity and tense morphemes to express time and use Chain formation (21b) instead of variable binding (21a) to establish referential dependencies. They further argue that in populations with weakened syntactic processing abilities, such as young children and patients with agrammatic Broca aphasia, syntax is equally economical as other, extra-syntactic, modules. This explains their omission of articles, use of root infinitives, the PIP and other non-target-like performance at the syntax-discourse interface. On the other hand, syntactic operations or constructions that do not interface with discourse, such as the syntactic position of functional heads, are predicted to be relatively robust.

If the PIP is not the result of incomplete acquisition, nor of a loss of linguistic structures, it is predicted that agrammatic patients that speak Spanish should show a similar response pattern to Spanish-speaking children. They should show a PIP in those constructions in which cross-modular economy considerations play a role, but not in other constructions. Baauw and Cuetos (2003) performed a picture verification task in which four patients, diagnosed with agrammatic Broca's aphasia, participated. They were aged between 48 and 64 years. In the experiment the interpretation of reflexives and pronouns was tested. The pronouns were tested in simple transitive sentences (22a) and in ECM sentences (22b). The results showed that the patients rejected the reflexive interpretation of (22a) $79 \%$ of the time, but only $21 \%$ of the time in (22b).

\begin{tabular}{|c|c|c|c|c|c|}
\hline 22. a. & $\begin{array}{l}\text { La niña } \\
\text { the girl }\end{array}$ & $\begin{array}{l}\text { la } \\
\text { her }\end{array}$ & $\begin{array}{l}\text { tocó } \\
\text { touched }\end{array}$ & & [la $=$ la niña, $21 \%$ acceptance $]$ \\
\hline b. & $\begin{array}{l}\text { La niña } \\
\text { the girl }\end{array}$ & $\begin{array}{l}\text { la } \\
\text { her }\end{array}$ & $\begin{array}{l}\text { vio } \\
\text { saw }\end{array}$ & $\begin{array}{l}\text { bailar } \\
\text { dance }\end{array}$ & [la $=$ la niña, $79 \%$ acceptance $]$ \\
\hline
\end{tabular}

This shows that agrammatic patients, like children, accept a bound variable interpretation of the clitic pronoun in contexts in which Reinhart and Reuland's (1993) Principle B plays no role, as in (22b), but that they reject a local co-reference interpretation in (22a), where binding of the clitic pronoun would lead to a violation of Principle B. This shows that agrammatic patients, like children, do not violate Principle B, but also that both populations analyze Spanish weak pronouns as syntactic clitics, making a local co-reference construal impossible. As has been argued before, children acquire the syntactic properties of clitic pronouns early. Since the syntactic position of the clitic functional head is not subject to any cross-modular economy consideration, this property of syntax is relatively robust. 
Therefore, children hardly make mistakes with this aspect of grammar and agrammatic patients do not lose these properties. ${ }^{7}$

\subsection{Task Effects}

Another argument that supports a processing account of the PIP is its sensitivity to task effects. Baauw et al. (2011) argued that children perform more target-like on experimental methods that require fewer processing resources. Concretely, they show that the intensity of the PIP, both in children and agrammatic patients, differs according to the used research method, picture verification tasks, leading to higher rates of non-target-like performance than less demanding picture selection tasks.

Following Baauw et al. (2011), we assume that children, when they hear a sentence with a pronoun, will try to resolve the pronoun in a way that avoids violating constraints on local binding (Principle B, but also economy considerations involving bound variable construals) and, depending on the language, constraints on local co-reference (Rule I). This makes the extra-sentential DP the preferred antecedent but, depending on contextual or task-related factors, the sentence internal antecedent may also be considered.

Given this strategy, the picture selection task and the picture verification task impose different processing demands on the child. In the picture selection task that we will consider, the child is presented a test sentence (for example John is washing him) and tree pictures. One picture represents the "reflexive" action (for instance, John washing himself), another one represents a "transitive" action (John washing Peter), and a third one a non-related action (John filming somebody). The child must point at the picture that best matches the meaning of the test sentence. In the picture verification task, on the other hand, the child is presented a test sentence and one picture. This picture represents either a "reflexive" action or an action performed by one individual to another individual, and the child must decide whether the content of the picture matches the test sentence by saying "yes" or "no". When the test sentence is a pronoun, adult speakers with no language pathologies will say "yes" when the picture represents a non-reflexive action, and "no" when the picture represents a reflexive action.

It is clear that in the case of the picture selection task the child can avoid considering an interpretation that involves cross-modular economy considerations or reference set calculations, by choosing the picture representing the "transitive" interpretation. In the case of a picture verification task, this freedom is not offered to the child. The child is "forced" to consider the possibility of a local co-reference or binding interpretation, which will often lead to non-target-like responses because of the processing demands that this interpretation imposes on the child.

In Baauw et al. (2011) this prediction was tested by comparing results on picture selection experiments with Spanish-speaking children and agrammatic patients, with earlier results of studies that used a picture verification task.

In a picture selection study, 38 Spanish-speaking children ranging between $5 ; 3$ and $6 ; 2$ years old (mean age 5;9) were tested on sentences containing reflexives, pronouns in simple transitive sentences (such as 16b), and pronouns in ECM sentences (such as 16a). The results show that they scored $94 \%$ target-like on the interpretation of pronouns in simple transitive sentences, and $75 \%$ target-like on the interpretation of pronouns in ECM sentences. These results were compared with the percentage correct "no" responses on trials testing pronouns that elicited "no" responses in adults without language pathology, provided by several picture verification (PV) studies: PV-1 (Baauw et al. 1997; Baauw and Cuetos 2003), PV-2 (Baauw 2000) and PV-3 (Alija and Baauw 2005). In Figure 1 the results from both the Picture Selection (PS) and Picture Verification (PV) studies are presented.

7 It has been reported that Spanish agrammatic patients, unlike Spanish children (Wexler et al. 2004), often omit object pronouns. Importantly though, when they use them they are in the correct position (Reznik et al. 1995). This indicates that the underlying syntactic structure of clitics is preserved in agrammatism. 


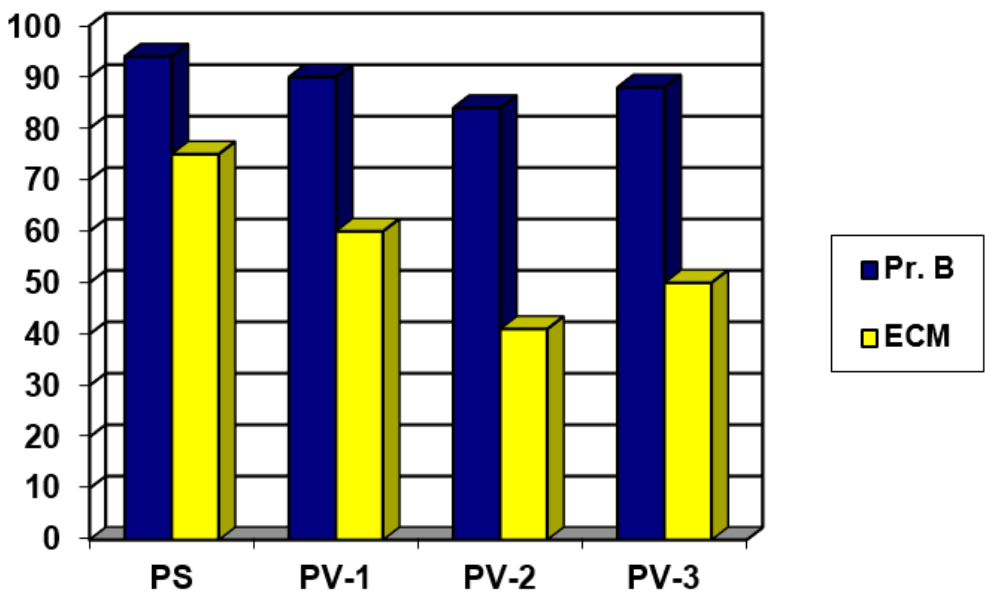

Figure 1. Percentage of target-like performance. Pr. B: simple transitive sentences; ECM: Exceptional Case Marking sentences; PS: Picture Selection; PV: Picture Verification.

As can be seen, children score at ceiling in simple transitive sentences, in all studies, independently of the used method. In the ECM sentences, on the other hand, we see that children scored systematically less target-like in the PV studies (around 50\% target-like) than in the PS study (75\% target-like).

A similar comparison was carried out with Spanish-speaking agrammatic patients. In a picture selection study, 7 agrammatic patients ranging from 42 to 68 years of age were tested with the same materials as in the child study reported above (only the number of trials per sentence type was expanded). The patients scored $89 \%$ target-like in simple transitive sentences and $61 \%$ target-like in the ECM sentences. In Figure 2 these results are compared with the PV-task results on the pronominal "no" trials from Baauw and Cuetos (2003).

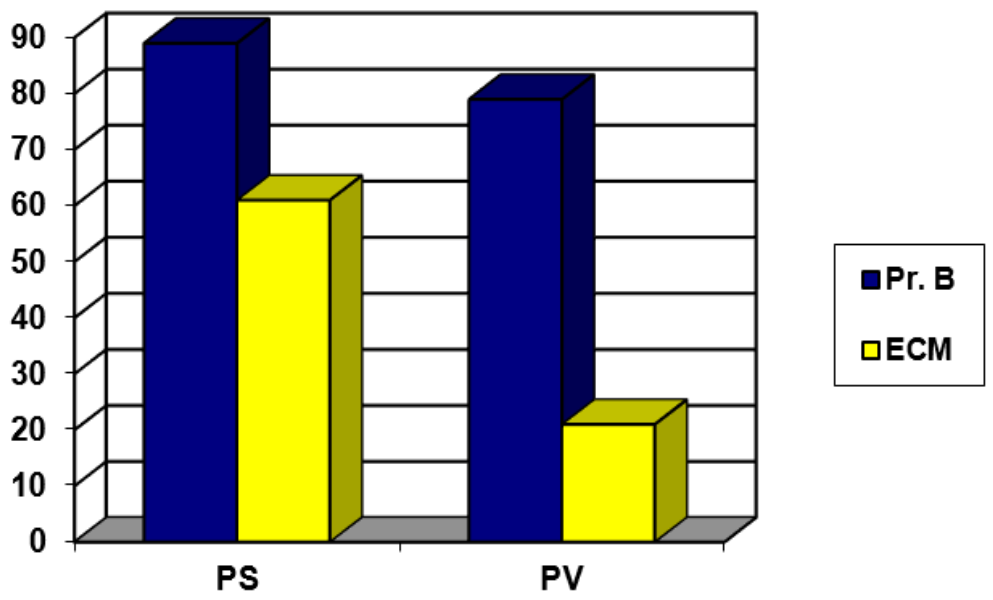

Figure 2. Percentage of target-like performance.

As we can see, the patients scored highly target-like on the simple transitive sentences, in both studies, but scored considerably less target-like on ECM sentences in the PV study than in the PS study.

These results are confirmed by a combined PS/PV experiment presented in Baauw et al. (2011). In this experiment 20 Dutch-speaking children (ranging from $4 ; 11$ to $6 ; 0$, mean age $4 ; 10$ ) were presented a test in which PS and PV items alternated. In the test, three sentence types were tested: reflexives, pronouns in simple transitive sentences, and pronouns in ECM sentences. The results on the pronominal trials are presented in Figure 3. 


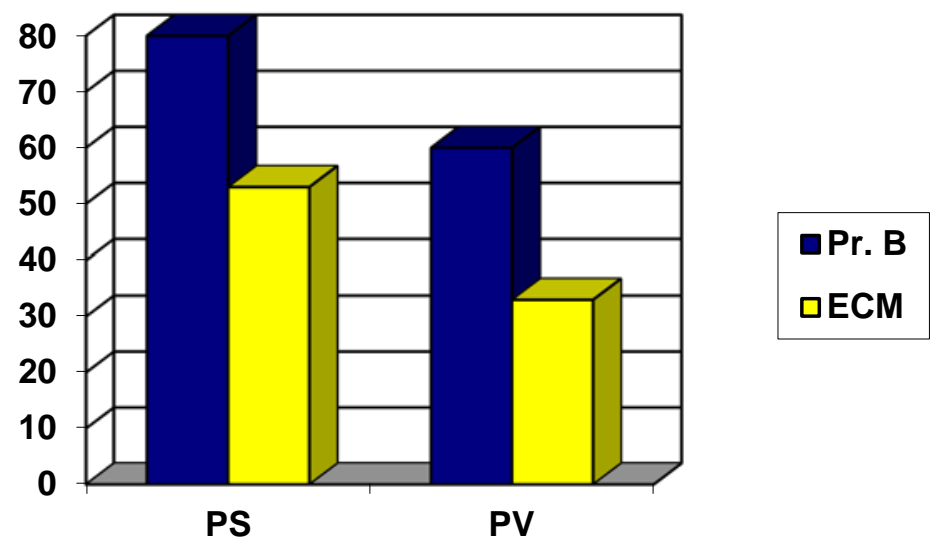

Figure 3. Percentage of target-like performance.

The results clearly show a statistically significant effect of both methodology (PS vs. PV) and construction (Pr. B vs. ECM).

Finally, the effect of task is also confirmed by van Rij et al. (2010). They tested 75 Dutch-speaking children in a picture verification task, in which the test sentences were presented at different speech rates. The assumption is that at high speed rates the analysis and interpretation of pronouns require more processing resources. The results showed that a reduction in speech rate affected the interpretation of pronouns positively.

\section{Conclusions}

In this paper, we have argued that the PIP can best be viewed as the result of an interaction between language specific properties of predicates and pronouns on the one hand, and a processing limitation that affects children's ability to carry out reference set calculations and to apply cross-modular economy principles in a target-like way (Grodzinsky and Reinhart 1993; Avrutin 2004, 2006).

The language-specific properties of pronouns account for the observed cross-linguistic differences between languages without syntactic clitic pronouns, such as Dutch and English, on the one hand, and languages that have syntactic clitics, such as Spanish, on the other hand. This property of Spanish syntax, which is acquired early, accounts for the virtual absence of a PIP in simple transitive sentences, such as the Spanish counterparts of the girl pointed at her, and the weaker PIP in ECM sentences such as the girl saw her dance. The impossibility of clitic pronouns (or the null-object that they are associated with) to enter a local co-reference relation with the subject prevents Rule I from being invoked, to the effect that it cannot "break down" either. Romance strong pronouns, on the other hand, are predicted to give rise to a PIP in young children. Evidence from Italian acquisition suggests that strong direct object pronouns do indeed give rise to such an effect. Spanish strong direct object pronouns do not give rise to a PIP, probably because they are obligatorily doubled by a clitic pronoun. When strong pronouns are the complement of a preposition, the increased acceptance of the reflexive interpretation by Spanish-speaking children is most likely due to their more frequent analysis of PPs as separate binding domains.

The syntactic properties of ECM sentences explain why Dutch-speaking children show a stronger PIP in this construction. In addition to their problems with the application of Rule I, their weaker syntactic processing capacity changes the economy relation between referential dependencies formed in syntax (A-Chains between simple reflexives and local DPs) and pronominal bound variable relations. This leads them to accept the embedded subject pronoun of the ECM sentence to be bound by the main clause subject DP. Spanish-speaking children are not affected by a breakdown of Rule I, due to the clitic status of Spanish weak pronouns, but they are affected by the changed economy relation between syntactic and extra-syntactic referential dependencies. This explains the presence of a PIP in their ECM sentences, but a weaker one than Dutch-speaking children show in these constructions. 
A processing account of the PIP explains many of the experimental results presented in this paper. It accounts for the variability of the PIP, for its presence in adults affected by agrammatic Broca's aphasia, for its absence in production, and for its sensitivity to task effects. It also has the advantage that it does not face the kind of learnability problems that alternative approaches face. This does not mean that the child does not need to learn anything to perform in an adult-like manner on the interpretation of pronouns; the child needs to learn the syntactic properties of pronouns, such as whether the pronoun to be learned is a syntactic clitic or not. However, to acquire these properties, the child arguably receives sufficient relevant examples from the input. In fact, research shows that children acquire these properties at an early stage of acquisition (Ezeizabarrena 1996; Guasti 1994).

Conflicts of Interest: The author declares no conflict of interest.

\section{References}

Alija, Maira, and Sergio Baauw. 2005. La Interpretación de los Pronombres Masculinos y Femeninos por Niños Neerlandeses y Españoles [The Interpretation of Masculine and Feminine Pronouns by Dutch and Spanish Children]. Cognitiva 17: 3-28.

Aoun, Joseph. 1999. Clitic doubled arguments. In Beyond Principles and Parameters. Edited by Kyle Johnson and Ian Roberts. Dordrecht: Kluwer Academic Publishers.

Avrutin, Sergey. 1994. Psycholinguistic Investigations in the Theory of Reference. Unpublished Ph.D. dissertation, MIT, Cambridge, MA, USA.

Avrutin, Sergey. 2004. Optionality in child and aphasic speech. Lingue e Linguaggio 1: 67-69.

Avrutin, Sergey. 2006. Weak Syntax. In Broca's Region. Edited by Yosef Grodzinsky and Katrin Amunts. Oxford: Oxford University Press, pp. 49-62.

Avrutin, Sergey, and Sergio Baauw. 2013. A processing view on agrammatism. In Diagnosing Syntax. Edited by Lisa Lai-Shen Cheng and Norbert Corver. Oxford: Oxford University Press, pp. 397-411.

Avrutin, Sergey, and Kenneth Wexler. 1992. Development of Principle B in Russian: Coindexation at LF and Coreference. Language Acquisition 4: 259-306. [CrossRef]

Avrutin, Sergey, Stuart Lubarsky, and Jennifer Greene. 1999. Comprehension of Contrastive Stress by Agrammatic Broca's Aphasics. Brain and Language 70: 163-86. [CrossRef] [PubMed]

Baauw, Sergio. 2000. Grammatical Features and the Acquisition of Reference. A Comparative Study of Dutch and Spanish. Ph.D. dissertation, Utrecht University, Utrecht, The Netherlands. Utrecht: LOT.

Baauw, Sergio, and Fernando Cuetos. 2003. The interpretation of pronouns in Spanish language acquisition and breakdown: Evidence for the "Principle B Delay" as a Non- unitary phenomenon. Language Acquisition 11: 219-75. [CrossRef]

Baauw, Sergio, María A. Escobar, and William Philip. 1997. A Delay of Principle B Effect in Spanish Speaking Children: The Role of Lexical Feature Acquisition. In Proceedings of the GALA'97 Conference on Language Acquisition. Edited by Conxita Lleó, Antonella Sorace, Caroline Heycock and Richard Shillcock. Edinburgh: Human Communication Research Centre.

Baauw, Sergio, Shalom Zuckerman, Esther Ruigendijk, and Sergey Avrutin. 2011. Principle B Delays as a processing problem: Evidence from task effects. In Production-comprehension Asymmetries in Child Language. Edited by Angela Grimm, Anja Müller, Cornelia Hamann and Esther Ruigendijk. Berlin: De Gruyter, pp. 247-72.

Berger, Carola V. 1999. De Verwerving van Anaforische Relaties in het Italiaans: Een Onderzoek naar Lexical Feature Learning. [The Acquisition of Anaphoric Relations in Italian: An Investigation in Lexical Feature Learning]. Master's Thesis, Utrecht University, Utrecht, The Netherlands.

Bloom, Paul, Andrew Barss, Janet Nicol, and Laura Conway. 1994. Children's knowledge of binding and coreference: Evidence from spontaneous speech. Language 70: 53-71. [CrossRef]

Chien, Yu-Chin, and Kenneth Wexler. 1990. Children's knowledge of locality conditions in binding as evidence for the modularity of syntax and pragmatics. Language Acquisition 1: 225-95. [CrossRef]

Chomsky, Noam. 1981. Lectures on Government and Binding. Dordrecht: Foris Publications.

Conroy, Anastasia, Eri Takahashi, Jeffrey Lidz, and Colin Phillips. 2009. Equal treatment for all antecedents: How children succeed with Principle B. Linguistic Inquiry 40: 446-86. [CrossRef] 
Crain, Stephen, and Rosalind Thornton. 1998. Investigations in Universal Grammar: A Guide to Experiments on the Acquisition of Syntax and Semantics. Cambridge: MIT Press.

Delfitto, Denis. 2002. On the Semantics of Pronominal Clitics and Some of Its Consequences. Catalan Journal of Linguistics 1: 41-69. [CrossRef]

Di Sciullo, Anna Maria, and Calixto Agüero-Bautista. 2008. The Delay of Principle B Effect (DPBE) and its absence in some languages. Language and Speech 51: 77-100. [CrossRef] [PubMed]

Elbourne, Paul. 2003. Are our children speaking Middle English? Paper presented at CUNY Syntax Supper.

Elbourne, Paul. 2005. On the acquisition of Principle B. Linguistic Inquiry 36: 333-65. [CrossRef]

Escobar, Linda, and Anna Gavarró. 1999. The Acquisition of Catalan Clitics and Its Implications for Complex Verb Structure. Report de Recerca, Rep. No. GGT-99-3; Barcelona: Universitat Autònoma de Barcelona.

Ezeizabarrena, María José. 1996. Adquisición de la Morfología Verbal en Euskera y Castellano por Niños Bilingües. Unpublished Ph.D. thesis, University of Hamburg, Hamburg, Germany.

Fernández-Soriano, Olga. 1989. Strong pronouns in null-subject languages and the avoid pronoun principle. In Proceedings of the Student Conference on Linguistics 1989. MIT Working Papers in Linguistics 11. Edited by P. Branigan, J. Gaulgin, M. Kubo and K. Murasugi. Cambridge: MIT Press.

Fodor, Janet. 1992. Designated Triggers versus the Subset Principle. Unpublished manuscript; New York: CUNY Graduate Center.

Grodzinsky, Yosef, and Tanya Reinhart. 1993. The Innateness of Binding and Coreference. Linguistic Inquiry 24: 69-102.

Grodzinsky, Yosef, Kenneth Wexler, Yu-Chin Chien, Susan Marakovitz, and Julie Solomon. 1993. The breakdown of binding relations. Brain and Language 45: 396-422. [CrossRef] [PubMed]

Guasti, Maria Teresa. 1994. Verb syntax in Italian child grammar: finite and non-finite verbs. Language Acquisition 3: 1-40. [CrossRef]

Hamann, Cornelia, Odette Kowalski, and William Philip. 1997. The French 'Delay of Principle B Effect'. In Proceedings of the Annual Boston University Conference on Language Development 21. Edited by Elizabeth Hughes, Mary Hughes and Annabel Greenhill. Somerville: Cascadilla Press.

Heim, Irene, and Angelika Kratzer. 1998. Semantics in Generative Grammar. Oxford: Blackwell.

Hestvik, Arild, and William Philip. 2000. Binding and Coreference in Norwegian Child Language. Language Acquisition 8: 171-235. [CrossRef]

Jakubowicz, Celia. 1984. On Markedness and Binding Principles. In Proceedings of the Northeastern Linguistic Society. Edited by Charles Jones and Peter Sells. Amherst: GLSA, University of Massachusetts, vol. 14.

Kolk, Herman. 1987. A theory of grammatical impairment in aphasia. In Natural Language Generation. Edited by Gerard Kempen. Dordrecht: Kluwer.

Koster, Charlotte. 1993. Errors in Anaphora Acquisition. Ph.D. dissertation, Utrecht University, Utrecht, The Netherlands.

Lyczkowsky, David Alan. 1999. Adquiéretelo: On the Acquisition of Pronominal Object Clitics in Spanish. Bachelor's thesis, Harvard University, Cambridge, MA, USA.

Manzini, M. Rita, and Kenneth Wexler. 1987. Parameters, binding theory, and learnability. Linguistic Inquiry 18: 413-44.

Margócsy, D. 2000. Pronouns in Hungarian. Master's thesis, Utrecht University College, Utrecht, The Netherlands.

McDaniel, Dana, and Thomas L. Maxfield. 1992. Principle B and contrastive stress. Language Acquisition 2: 337-58. [CrossRef]

McKee, Cecile. 1992. A comparison of pronouns and anaphors in Italian and English acquisition. Language Acquisition 2: 21-54. [CrossRef]

Menuzzi, Sergio. 1996. Constraint interaction in binding. In Linguistics in the Netherlands. Edited by Crit Cremers and Marcel den Dikken. Amsterdam and Philadelphia: John Benjamins Publishing Company.

Neeleman, Ad, and Fred Weerman. 1999. Flexible Syntax: A Theory of Case and Arguments. In Studies in Natural Language and Linguistic Theory. Dordrecht: Kluwer Academic Publishers, vol. 47.

Philip, William, and Peter Coopmans. 1996. The role of lexical feature acquisition in the development of pronominal anaphora. In Amsterdam Series on Child Language Development. Edited by William Philip and Frank Wijnen. Amsterdam: Instituut Algemene Taalwetenschap, vol. 5.

Reinhart, Tanya, and Eric Reuland. 1993. Reflexivity. Linguistic Inquiry 24: 657-720.

Reuland, Eric. 2001. Primitives of Binding. Linguistic Inquiry 32: 439-92. [CrossRef] 
Reznik, Magdalena, Silvia Dubrovsky, and Silvia Maldonado. 1995. Agrammatism in Spanish: A Case Study. Brain and Language 51: 355-68. [CrossRef] [PubMed]

Ruigendijk, Esther, Nada Vasić, and Sergey Avrutin. 2006. Reference Assignment: Using Language Breakdown to Choose Between Theoretical Approaches. Brain and Language 96: 302-17. [CrossRef] [PubMed]

Schaeffer, Jeannette. 1997. On the acquisition of object placement in Dutch and Italian. In Proceedings of the GALA '97 Conference on Language Acquisition. Edited by Antonella Sorace, Caroline Heycock and Richard Shillcock. Edinburgh: Human Communication Research Centre.

Sigurjónsdóttir, Sigríður. 1992. Binding in Icelandic: Evidence from Language Acquisition. Ph.D. dissertation, University of California, Los Angeles, CA, USA.

Sportiche, Dominique. 1992. Clitic Constructions. Unpublished manuscript; Los Angeles: University of California.

Thornton, Rosalind, and Kenneth Wexler. 1999. Principle B, VP Ellipsis and Interpretation in Child Grammar. Cambridge: MIT Press.

van Rij, Jacolien, Hedderik Van Rijn, and Petra Hendriks. 2010. Cognitive architectures and language acquisition: A case study in pronoun comprehension. Journal of Child Language 37: 731-66. [CrossRef] [PubMed]

Varlokosta, Spyridoula. 2000. Lack of Clitic-Pronoun Distinctions in the Acquisition of Principle B in Child Greek. In Proceedings of the 24th Annual Boston University Conference on Language Development 24. Edited by S. Catherine Howell, Sarah A. Fish and Thea Keith-Lucas. Somerville: Cascadilla Press.

Vasic, Nada. 2006. Pronoun Comprehension in Agrammatic Aphasia. Ph.D. dissertation, Utrecht University, Utrecht, The Netherlands. Utrecht: LOT.

De Villiers, Jill, Jacqueline Cahillane, and Emily Altreuter. 2005. Touchy subject: Optimality and coreference. Unpublished manuscript. Smith College.

Wexler, Kenneth, Anna Gavarró, and Vicenç Torrens. 2004. Feature checking and object clitic omission in child catalan and Spanish. In Romance Languages and Linguistic Theory 2002. Edited by Reineke Bok-Bennema, Bart Hollebrandse, Brigitte Kampers Manhe and Petra Sleeman. Amsterdam: John Benjamins.

(C) 2018 by the author. Licensee MDPI, Basel, Switzerland. This article is an open access article distributed under the terms and conditions of the Creative Commons Attribution (CC BY) license (http:// creativecommons.org/licenses/by/4.0/). 